\title{
ANALISA PENCARIAN RUTE TERCEPAT MENUJU TEMPAT WISATA PULAU KUMALA KOTA TENGGARONG MENGGUNAKAN ALGORITMA GREEDY
}

\author{
Harming Puja Kekal ${ }^{1}$, Windu Gata ${ }^{2}$, Siti Nurdiani ${ }^{3}$, Andi Jati Setio Rini ${ }^{4}$, Deviana Sely Wita ${ }^{5}$ \\ ${ }^{12345}$ Program Studi Magister Ilmu Komputer STMIK Nusa Mandiri Jakarta \\ Jl. Margonda Raya No. 545 Depok City \\ E-mail: ${ }^{1} 14002622 @$ nusamandiri.ac.id, ${ }^{2}$ windu@ nusamandiri.ac.id, \\ ${ }^{3}$ siti.sxd@nusamandiri.ac.id, ${ }^{4} 14002632 @$ nusamandiri.ac.id, ${ }^{5} 14002609 @$ nusamandiri.ac.id
}

\begin{abstract}
ABSTRAK
Pada saat kita hendak berpergian seringkali memikirkan sebuah rute perjalanan yang akan dilalui. Maka dari itu perlu ditentukan sebuah alternatif perjalanan menuju tempat wisata dari tempat satu ke tempat lainnya supaya sampai dengan cepat. Selain itu kita harus mempertimbangkan waktu agar tidak terlalu lama membuang waktu dalam perjalanan. Penelitian ini bertujuan untuk menentukan rute tercepat dari Samarinda (ring road) (node A) ke Pulau Kumala (node $\mathrm{H}$ ) dengan mempertimbangkan jarak dan waktu menggunakan algoritma greedy. Dalam hal ini terdapat tiga pilihan rute perjalanan dari node $A$ menuju node $H$. Pilihan rute pertama yaitu dari node $A \rightarrow C \rightarrow F \rightarrow G \rightarrow H$, kemudian rute kedua yaitu dari node $\mathrm{A} \rightarrow \mathrm{B} \rightarrow \mathrm{D} \rightarrow \mathrm{F} \rightarrow \mathrm{G} \rightarrow \mathrm{H}$, dan rute yang ketiga yaitu $\mathrm{A} \rightarrow \mathrm{B} \rightarrow \mathrm{E} \rightarrow \mathrm{G} \rightarrow \mathrm{H}$. Untuk menentukan rute perjalanan dengan jarak terpendek dan waktu yang cepat dapat dilakukan dengan menggunakan solusi pendekatan algoritma Greedy. Algoritma Greedy membentuk solusi langkah per langkah dan terdapat beberapa pilihan yang memberikan hasil terbaik dengan membuat pilihan optimum lokal pada setiap langkah sehingga diperoleh solusi optimum global. Metode pengumpulan data menggunakan teknik studi literatur, observasi dan wawancara dalam memahami permasalahan objek penelitian selanjunya dilakukan alur penelitian untuk memudahkan dalam implementasi analisa pemilihan rute. Berdasarkan hasil dan pembahasan pada objek penelitian diperoleh hasil penelitianpencarian rute terpendek dari node A menuju node $\mathrm{H}$ yaitu rute dari Ring Road $\rightarrow$ Pusaka $\rightarrow$ Polowali $\rightarrow$ Teluk Dalam $\rightarrow$ Pulau Kumala dan dinyatakan dengan node rute $A \rightarrow B \rightarrow E \rightarrow G \rightarrow H$ dengan jarak 20 Kilometer.
\end{abstract}

Kata Kunci : Algoritma Greedy, Rute Tercepat, Tur

\section{ABSTRACT}

When we want to travel often think of a route that will be traveled. Therefore, it is necessary to determine an alternative trip to the tourist attraction from one place to another in order to arrive quickly. In addition we must consider the time so as not to waste too long time on the trip. This study aims to determine the fastest route from Samarinda (ring road) (node A) to Kumala Island (node H) by considering distance and time using greedy algorithms. In this case there are three choices of route from node $A$ to node $H$. The first route choice is from node $A \rightarrow C \rightarrow F \rightarrow G \rightarrow H$, then the second route is from node $A \rightarrow B \rightarrow D \rightarrow F \rightarrow G \rightarrow H$, and the third route is $A \rightarrow B \rightarrow E \rightarrow G \rightarrow H$. To determine the route of travel with the shortest distance and fast time can be done using greedy algorithm approach solution. . Greedy algorithms form step-by-step solutions and there are several options that deliver the best results by making local optimum choices at each step so that global optimum solutions are obtained. Data collection method using literature study techniques, observation and interviews in understanding the problem of research object next to the research flow to facilitate the implementation of route selection analysis. Based on the results and discussion on the research object obtained the results of research search for the shortest route from node $A$ to node $H$, namely the route from Ring Road $\rightarrow$ Pusaka $\rightarrow$ Polowali $\rightarrow$ Teluk Dalam $\rightarrow$ Kumala Island and declared with route node $A \rightarrow B \rightarrow E \rightarrow G \rightarrow H$ with a distance of 20 Kilometers.

Keywords : Greedy Algorithm, Fastest Route, Tour. 


\section{PENDAHULUAN}

Ketika akhir pekan maupun libur hari raya pencarian rute alternatif tercepat ke sebuah tempat wisata menjadi masalah yang sangat penting karena banyaknya jumlah wisatawan yang ingin pergi ke tempat wisata untuk menghabiskan waktu berliburnya. Namun, karena melonjaknya jumlah wisatawan yang membuat jalan menuju ke tempat wisata tersebut menjadi macet. Terjebak dalam kemacetan pastinya membuat seseorang menjadi jenuh dan bosan, sehingga mereka akan berusaha mencari cara agar perjalanan mereka menjadi tidak terhambat dan sampai ke tempat tujuan dengan waktu yang singkat dan cepat.

Salah satu solusinya yaitu dengan mengetahui rute alternatif tercepat agar terhindar dari kemacetan. Rute alternatif tercepat ini berguna untuk mendapatkan jarak dan waktu tempuh yang optimal dari tempat asal menuju tempat

tujuan tanpa terhambat oleh kemacetan yang disebabkan melonjaknya wisatawan.

Sebelumnya sudah ada penelitian yang menggunakan metode Algoritma Greedy untuk mencari rute terpendek, yaitu penelitian "Sistem Pencarian Hotel Berdasarkan Perjalanan Terpendek dengan Mempertimbangkan Daya Tarik Wisata Menggunakan Algoritma Greedy". Permasalahan dari penelitian sebelumnya adalah karena semakin banyaknya wisatawan yang berkunjung ke Indonesia untuk berwisata ini menyebabkan bertambahnya jumlah hotel untuk penginapan, Herli \& Raharjana,( 2015). Saat menentukan hotel sering kali menjadi masalah yang cukup penting bagi para wisatawan untuk mencari sebuah hotel yang letaknya berdekatan dengan tempat wisata maka solusi yang ditawarkan oleh penelitian sebelumnya adalah menawarkan sebuah rekomendasi layanan memilih hotel dan alur rute perjalanan wisata dengan tepat sesuai jarak perjalanan yang dipertimbangkan.

Sedangkan permasalahan dari penelitian yang kami lakukan yaitu analisa menentukan rute tercepat menuju Tempat wisata Pulau Kumala menggunakan Algoritma Greedy dengan mempertimbangan jarak. Hasil yang diperoleh dari penelitian ini yaitu sebuah alternatif rute terpendek menuju Pulau Kumala dari beberapa pilihan rute lainnya.

Penelitian ini bertujuan untuk melakukan observasi masalah yang dihadapi dan untuk menunjukkan atau menemukan solusi rute alternatif tercepat dari Kota Samarinda menuju Pulau Kumala dengan menggunakan metode algoritma Greedy. Sehingga diperoleh hasil penelitian yang dapat memberikan manfaat dan juga sebagai sarana media untuk berbagi informasi dari hasil analisa yang dilakukan dalam penelitian ini.

\section{TINJAUAN PUSTAKA}

\subsection{Rute}

Rute adalah jarak atau arah yang harus ditempuh dan dilalui dengan urut. Rute tercepat yaitu suatu jarak tempuh dari tempat asal menuju tempat tujuan yang dilalui dengan urut dan dilalui dalam kurun waktu tertentu Lebih tepatnya rute tercepat merupakan suatu lintasan minimum yang memerlukan waktu untuk mencapai satu tempat ke tempat tujuan lainnya.

\subsection{Algoritma Greedy}

Sebuah metode yang dapat memecahkan persoalan optimasi dengan cara bertahap melalui alur yang selalu berkembang hingga pemecahan permasalahan dapat teratasi, Herli \& Raharjana (2015). Algoritma Greedy dapat memilih sebuah rute yang diambil dahulu untuk memberikan suatu alternatif lokal agar menghasilkan alternatif optimal dengan menyeluruh sehingga diperoleh rute tercepat dari Madiun menuju ke Telaga Sarangan. Selain itu Algoritma Greedy juga membuat beberapa pilihan terbaik yang didapat ketika itu juga. Beberapa permasalahan optimasi dalam lingkup algoritma Greedy berikut yaitu Ghozali et al (2017):

a. Himpunan Kandidat (C) : Himpunan ini berisi sebuah elemen penilai pembentuk solusi. Tiap langkah kandidat diambil dari himpunannya.

b. Himpunan Solusi (S) : Himpunan kandidat yang terpilih menjadi solusi dari permasalahan.

c. Fungsi Seleksi : Merupakan fungsi yang tiap langkahnya memilih kandidat terbaik untuk menuju solusi optimal.

d. Fungsi Kelayakan (Feasible) : Dinyatakan fungsi kelayak apabila telah berhasil memeriksa kandidat untuk memberi solusi layak dan tidak melanggar kendala.

e. Fungsi Objektif : Fungsi yang berguna untuk memaksimalkan atau meminimalkan sebuah nilai solusi.

Untuk mencari rute tercepat atau lintasan:: terpendek dalam Algoritma Greedy dilakukan dengan rumus berikut

1. Pertama lakukan periksa sisi yang berhubungan dengan sisi pertama (lokasi pertama). Pilih sisi yang memiliki bobot 
(jarak) terkecil denga sisi berikutnya. Jarak tersebut merupakan menjadi rute terpendek pertama, dapat dimisalkan sebagai (L1).

2. Selanjutnya menentukan rute terpendek berikutnya dapat diminalkan (D) dengan cara sebagai berikut :

a) Untuk mencari rute berikutnya dengan rumus $D(i)=L 1+$ bobot sisi berikutnya. Dijelaskan jarak pertama dijumlahkan dengan bobot berikutnya. Jika terdapat rute lainnya, maka lakukan penjumlah jarak rute tersebut dengan jarak sebelumnya.

b) Pilih D(i) yang memiliki jarak terkecil, kemudian jika terdapat rute lainnya lakukan perbandingan. Jika rute lainnya tersebut memiliki jarak lebih kecil daripada $\mathrm{D}(\mathrm{i})$, maka rute tersebut merupakan rute yang akan diperhitungkan selanjutnya.

Untuk mencari lintasan terpendek berikutnya dapat dilakukan dengan menggunkan cara kedua di atas.

\subsection{Teori Graf}

Teori graf yaitu ilmu yang mempelajari tentang sifat- sifat grafik. Graf merupakan dari himpunan beberapa benda dan disebut dengan simpul. Simpul biasanya dihubungkan dengan garis panah dan saling terhubung. Banyak struktur graf yang dapat dipresentasikan, misalnya dalam pertemanan pada aplikasi Twitter. Pengguna Twitter merupakan simpul- simpulnya dan sisinya merupakan pengguna yang saling mengikuti satu sama lain. Selain itu graf juga dapat dipresentasikan pada jaringan di jalan raya dengan kota dimodelkan sebagai simpulnya (node). Jalan yang saling menghubungkan antar kota atau daerah disebut sebagai sisi (edge). Dan panjang dari jalan tersebut merupakan bobot atau jaraknya yaitu (weight).

Dalam elemen Graf $\mathrm{G}$ didefinisikan sebagai pesangan himpunan $(\mathrm{V}, \mathrm{E})$ dan dinotasikan sebagai berikut $\mathrm{G}=(\mathrm{V}, \mathrm{E}) . \mathrm{V}$ adalah himpunan tidak kosong dari sebuah simpul (Node) dan E adalah himpunan sisi (edge) yang menghubungkan antara sepasang simpul dan Node E (kosong). Node dalam suatu Graf dapat dilambangkan dengan huruf abjad seperti : a, b, c, d, ..., v, w, ... dengan bilangan asli seperti $1,2,3, \ldots$, atau dapat digabung dari keduanya. Untuk sisi yang menghubungkan

simpul $\mathrm{u}$ dengan $\mathrm{v}$ sehingga diperoleh notasi sebagai $\mathrm{e}=(\mathrm{u}, \mathrm{v}) \cdot \mathrm{b}$

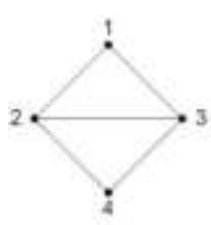

$G_{1}$

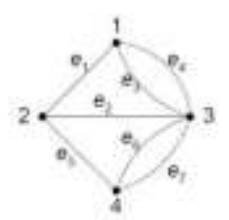

$G_{2}$

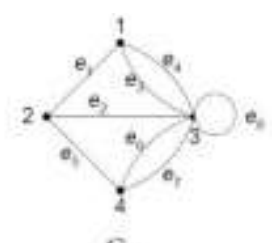

$G_{3}$
Gambar 2.1. $\left(\mathrm{G}_{1}\right)$ Graf Sederhana, $\left(\mathrm{G}_{2}\right)$ Graf Ganda, $\left(\mathrm{G}_{3}\right)$ Graf Semu.

Graf sederhana tidak memiliki gelang ataupun sisi yang ganda. Graf ganda memiliki sisi ganda. Sedangkan untuk graf semu memiliki gelang (loop). Graf semu banyak diketahui dibandingkan graf ganda, karena sisinya saling terhubung dengan graf semu tersebut,Saifulloh \& Fitriyani ( 2018).

\section{METODE YANG DIUSULKAN}

\subsection{Pengumpulan Data}

Dari penelitian yang akan dilakukan, peneliti dapat manunjukan suatu algoritma yang berfungsi untuk menghasilkan rute alternatif tercepat dengan menggunakan Algoritma Greedy. Teknik pengumpulan data yang dilakukan adalah sebagai berikut :

1. Studi Literatur : Dalam proses ini peneliti sebelumnya harus mempelajari dan memahami tentang Algoritma Greedy.

2. Dimana Algoritma Greedy dapat menganalisa dan mencari solusi secara cepat dalam menentukan rute alternatif pada saat tingkat kemacetan meningkat.

3. Wawancara : Dalam proses ini peneliti melakukan wawancara terhadap masyarakat untuk mencari tahu seringnya terjadi tingkat kemacetan dalam rute yang telah ditentukan dan wawancara mengenai rute yang terpendek.

4. Observasi : Observasi ini suatu kegiatan sebagai pengaplikasian suatu data yang bertujuan untuk memastikan data dari hasil wawancara benar dan akurat.

\subsection{Analisa Data dengan Algoritma Greedy}

Untuk menyimpulkan hasil penelitian tersebut maka dilakukan analisa data. Dimana data yang telah dipastikan valid dan akurat, selanjutnya akan dikumpulkan dan dikelompokkan untuk dianalisa menggunakan tahap analisa data dengan Algoritma Greedy. Berikut beberapa tahapannya :

1. Pengelompokan data : Dalam tahapan ini data yang yang telah terkumpul akan dikelompokan untuk dilakukan tahapan terhadap langkah- 
langkah perhitungan Algoritma Greedy untuk menghasilkan rute alternatif tercepat.

2. Penerapan data : Dalam proses ini data yang siap akan diaplikasikan untuk diperhitungkan dalam Algoritma Greedy.

Data hasil perhitungan Algoritma Greedy ini akan menghasilkan rute alternatif tercepat berguna untuk mendapatkan jarak dan waktu tempuh yang optimal dari tempat asal menuju tempat tujuan sehingga akan mempercepat jalan tempuh tanpa terhambat oleh kemacetan yang disebabkan melonjaknya wisatawan ketika hari libur.

Hasil dari Penelitian ini bertujuan untuk melakukan observasi masalah yang dihadapi dan untuk menunjukkan atau menemukan solusi rute alternatif tercepat dari Kota Samarinda menuju Pulau Kumala dengan menggunakan metode Algoritma Greedy. Sehingga diperoleh hasil penelitian yang dapat memberikan manfaat.

\subsection{Perancangan Sistem}

Dalam membangun sebuah sistem dengan menggunakan Algoritma Greedy, tahapan ini bertujuan untuk membantu kebutuhan pengguna

Dalam pengunaannya.

Dalam penerapan ini peneliti membangun terlebih dahulu Diagram Flowchart dimana dalam membangun program ini terdiri dari beberapa perintah yaitu input data, hasil pengolahan, dan riwayat pengolahan.

Untuk perancangan data yang didalamnya terdapat tahapan sebuah perintah inputan atau masukan dan outputan atau keluaran. Berikut tahapan-tahapannya :

1. Asal lokasi : Asal lokasi ini bertujuan sebagai inputan dimana pengguna akan memilih suatu titik lokasi yang telah ditentukan sistem yang keberadaan terdekat dengan asal lokasi pengguna.

2. Pemilihan rute alternatif tercepat : Pemilihan alternatif rute tercepat ini merupakan perhitungan dalam algoritma Greedy, dimana akan menunjukan sebuah alternatif rute tercepat yang akan ditempuh oleh pengguna.

3. Tingkat kemacetan : Tingkat kemacetan ini merupakan perhitungan system dari Algoritma Greedy, dimana sistem akan secara otomatis mencari rute yang tingkat kemacetan lebih sedikit dan rute tercepat dari jalur utama.

Berikut ini merupakan flowchart dari metodologi penelitian yang dilakukan :

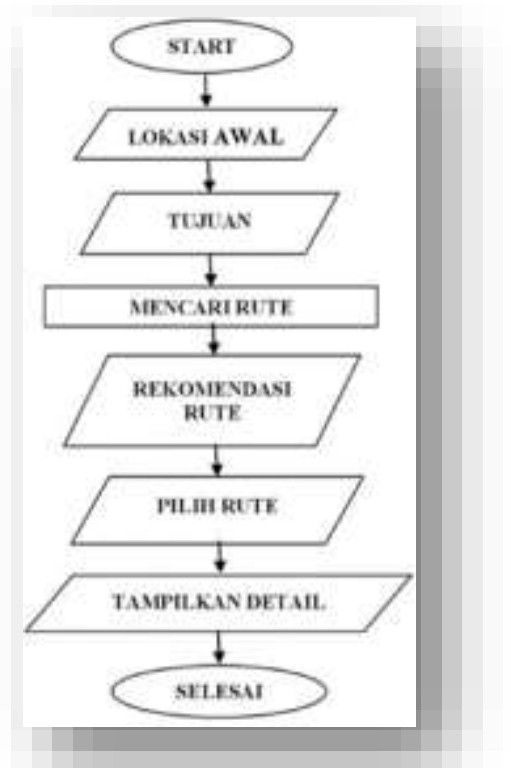

Gambar 3.1. Flowchart Pencarian RuteTerpendek

\section{HASIL PENELITIAN}

Nama-nama daerah yang akan dilalui mulai dari Samarinda sampai ke Pulau Kumala dimisalkan dengan huruf A sampai $\mathrm{H}$. Suatu daerah atau tempat akan dimisalkan dengan sebuah lingkaran (node). Nama-nama daerah terdapat dalam tabel berikut :

Tabel 4.1. Keterangan Nama Kota

\begin{tabular}{|c|c|}
\hline Node & Nama Daerah \\
\hline A & Ring road \\
\hline B & Pusaka \\
\hline C & Suryanata \\
\hline D & Jongkang Raya \\
\hline E & Polowali \\
\hline F & Mangkunegara \\
\hline G & Teluk Dalam \\
\hline H & Pulau Kumala \\
\hline
\end{tabular}

Implementasi dari Teori Graf ditunjukkan oleh node A sampai node $\mathrm{H}$, yang masing-masing memiliki jarak/ bobot (yang menunjukan jarak dari tiap-tiap node berikutnya, dimana dapat dimisalkan dengan gambar grafik 4.1 di bawah ini : 


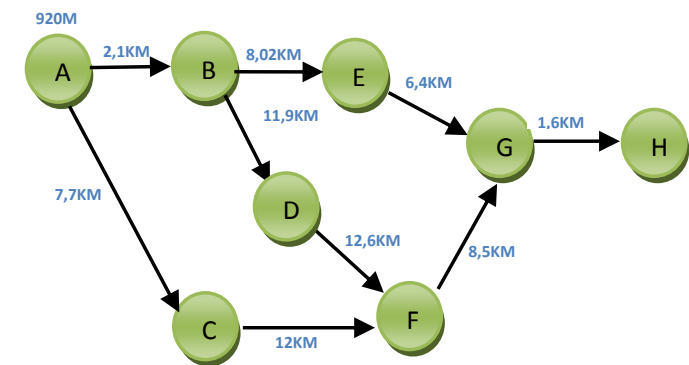

Gambar 4.1. Graf ruter dari tempat awal node

Dari lokasi awal (node A) terdapat 2 jalur yaitu melalui node A yang menuju ke node $\mathrm{B}$ atau sisi $\mathrm{AB}$ dengan jarak 2,1, dan node $\mathrm{A}$ yang menuju node $\mathrm{C}$ (sisi AC) dengan bobot jarak 7.7,Yang ditunjukan pada gambar 4.2 berikut ini :

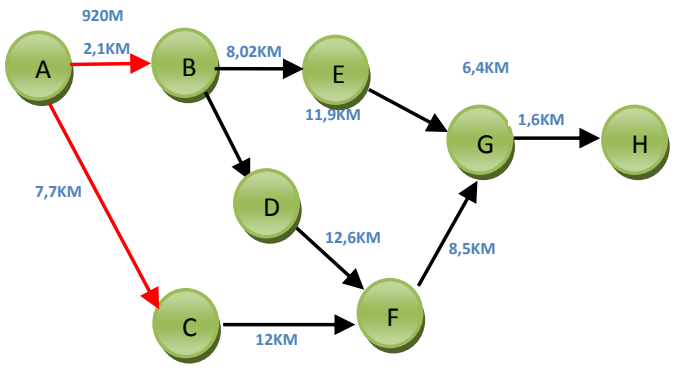

Gambar 4.2. Graf rute dari node $\mathrm{AB}$ dan $\mathrm{AD}$

Langkah selanjutnya kita memilih sisi yang berdekatan dengan sisi $\mathrm{AB}$ yaitu sisi $\mathrm{BE}$ yang memiliki jarak 8,02 sehingga totalnya menjadi 11,04. Sisi yang bedekatan dengan sisi BD yaitu sisi DF jengan jarak 11,9 sehingga total menjadi 24,5 dan sisi AC ya itu sisi CF dengan jarak 12 sehingga total menjadi 20,62 Grafik tersebut ditunjukan dalam gambar 4.3 berikut ini :

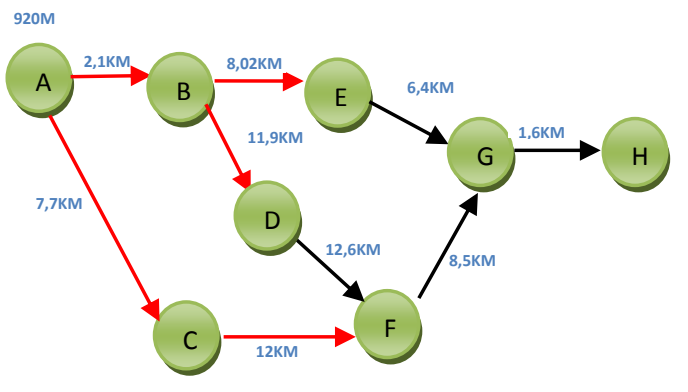

Gambar 4.3. Graf rute dari node BE,BD dan $\mathrm{CF}$

Dari sisi BD terdapat jalur baru yaitu sisi DF dengan bobot jarak 12,6 sehingga totalnya menjadi 27,52 Untuk pemilihan jalur pilih yang terkecil, dari masing-masing sisi, sisi yang lebih kecil yaitu sisi EG, grafik tersebut ditunjukan pada gambar 4.4 berikut ini :

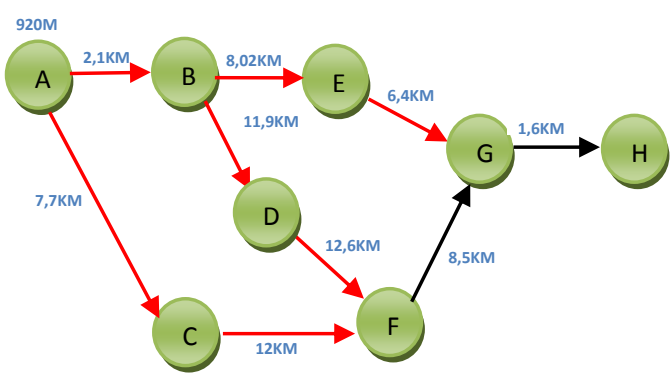

Gambar 4.4. Graf rute dari node DF dan EG

Selanjutnya memilih sisi yang berdekatan dengan DF yaitu sisi FG dengan bobot jarak 8,5 sehingga totalnya 36,02. Grafik tersebut ditunjukkan pada gambar 4.5 berikut ini :

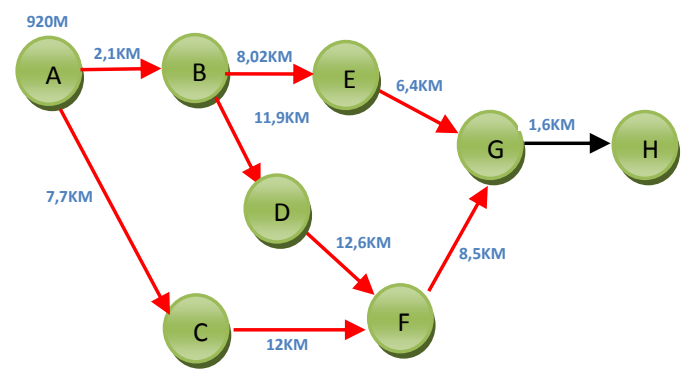

Gambar 4.5. Graf rute dari node DF dan FG

Selanjutnya memilih sisi yang berdekatan dengan EG yaitu sisi GH dengan bobot jarak 6,4 sehingga totalnya 20. Sedangkan sisi yang dekat dengan sisi FG adalah sisi $\mathrm{GH}$ yang mempunyai jarak 8,5, sehingga totalnya menjadi 31 . Grafik tersebut ditunjukkan oleh gambar 4.6 berikut ini :

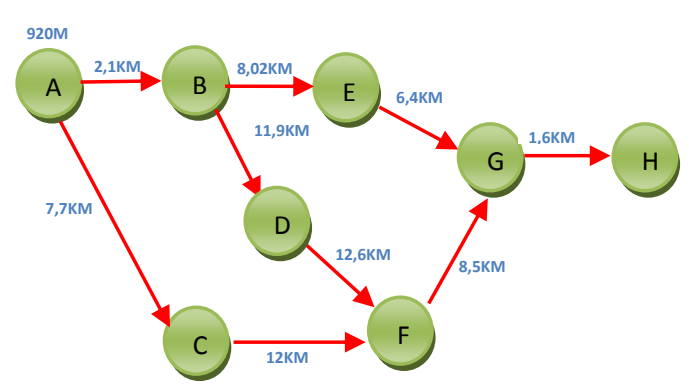

Gambar 4.6. Graf rute dari node GH 


\section{PENUTUP}

Dari Tiga pilihan rute alternatif yang ada dalam penelitian ini dan diperoleh hasil rute terpendek dari node $\mathrm{A}$

$\rightarrow \mathrm{B} \rightarrow \mathrm{E} \rightarrow \mathrm{G} \rightarrow \mathrm{H}$ dengan jarak $20 \mathrm{KM}$ yaitu Riang road $\rightarrow$ Pusaka $\rightarrow$ Polowali $\rightarrow$ Teluk Dalam $\rightarrow$ Pulau Kumala. Pencarian rute tercepat tersebut dapat membantu untuk menentukan sebuah rute tercepat dari tempat asal menuju tempat lain dengan mempertimbangkan jarak perjalanan. Dengan demikian kita tidak akan membuang banyak waktu dalam perjalanan.

Implementasi dalam algoritma Greedy yaitu mencari sebuah rute atau jalan alternatif terpendek yang memiliki jarak antar node.

Dalam hal ini penulis berharap kepada pembaca untuk mempertimbangkan suatu jarak dan waktu tempuh yang digunakan untuk sampai ke tempat tujuan dengan cepat. Selain itu penulis juga berharap agar pembaca dapat mengetahui rute terpendek untuk menuju ke Pulau Kumala.

\section{DAFTAR PUSTAKA}

[1] Levitin, A., Introduction to The Design \& Analysis of Algorithms, New Delhi India : Pearson Education, 2012.

[2 ]Efendi, F. S., Pinto, M., \& Tempake, H. S., Implementasi Algoritma Greedy Untuk Melakukan Graph Coloring : Studi Kasus Peta Provinsi Jawa Timur. Vol 4 edisi 2, 440-448, 2012.

[3] Herli, A. M., Indra K. R., Purbandini. "Sistem
Pencarian Hotel Berdasarkan Rute Perjalanan Terpendek Dengan Mempertimbangkan Daya Tarik Wisata Menggunakan Algoritma Greedy". Journal of Information Systems Engineering and Business Intelligence. Vol 1, No 1, April 2015.

[4] Ghozali1, A. E., Budi D. S., M. Tanzil F, "Aplikasi Perencana Wisata di Malang Raya dengan Algoritma Greedy", Jurnal Pengembangan Teknologi Informasi dan Ilmu Komputer, Vol 1, No. 12, Desember 2017.

[5] Jakaria, Ribangun Bamban, Mochamad A. R., "Implementasi Algoritma Greedy Pada Metode Transportasi Dengan Menggunakan Vam Dalam Pendistribusian Produk", Spektrum Industri, Vol 15, No. 1, 1-199, 2017.

[6] Raja Sabaruddin, "Solusi Optimum Minmax 0/1 Knapsack Menggunakan Algoritma Greedy", Jurnal Evolusi, Volume 4 Nomor 2, 2016, evolusi.bsi.ac.id.

[7] Alamsyah, Indriani T., P., "Penerapan Greedy Coloring Algorithm Pada Peta Kota Madya Yogyakarta Berbasis Four-Colour Theorem", Kaunia Vol. XI No. 1, 1436: 19- 26, April 2015.

[8] Saifulloh, S., \& Fitriyani, R. E. (2018). Analisa Pencarian Rute Tercepat Menuju Telaga Sarangan Menggunakan Algoritma Greedy. Jurnal Teknologi Dan Ilmu Komputer Prima (JUTIKOMP), $\quad 1(1), \quad 1-5$. https://doi.org/10.34012/jutikomp.v1i1.231

[9] (2018). Wikipedia. "Teori Graf". (Online). https://id.wikipedia.org/wiki/Teori_graf. Diakses pada tanggal 11 Juli 2018. 